\title{
Synthesis of nitrogen-doped mesoporous carbon using templating technique
}

\author{
S.Anandan ${ }^{1}$, A.Vinu $^{1 *}$, T.Mori $^{1}$ and K.Ariga ${ }^{2}$ \\ ${ }^{1}$ Nano-ionics Materials Group, ${ }^{2}$ Supermolecules Group, NIMS, 1-1 Namiki, Tsukuba, Ibaraki 3050044 , Japan. \\ Email: vinu.ajayan@nims.go.jp,
}

\begin{abstract}
:
$\mathrm{N}$-doped mesoporous carbon with three dimensional and cage type pore structure has been synthesized for the first time via templating process using three dimensional cage type mesoporous silica (KIT-6) and aniline as the template and the nitrogen source, respectively. Ammonium peroxy sulfate, $\mathrm{NH}_{4} \mathrm{~S}_{2} \mathrm{O}_{8}$, was used to polymerize the aniline molecules. The obtained material has been unambiguously characterized by various sophisticated techniques such as powder X-ray diffraction, nitrogen adsorption measurement, CHN analysis, and x-ray photoelectron spectroscopy. The XRD results revealed that the material exhibits a well ordered three dimensional mesoporous structure. Nitrogen adsorption data indicates that the material possesses very high surface area and pore volume.
\end{abstract}

Key words: Nitrogen-doped; mesoporous carbon; aniline: mesoporous silica

\section{INTRODUCTION}

Porous carbon materials have attracted much attention due to their remarkable performance in the fields of biomolecule adsorption, nanotechnology and fuel cells. In particular carbon materials with well ordered mesoporous structures are of great interest mainly due to their applications in catalysts, adsorbents, carriers in the energy storage, gas ghosts, or as components of electrodes $[1,2]$. There have been so many reports available in the literature for the preparation of mesoporous carbon with ordered structure using hard templating technique and other processes. Microporous zeolites [3] and mesoporous silicas [4] have been used as inorganic templates for the preparation of porous carbon with well-ordered structures using various carbon sources $[5,6]$ including sucrose, furfuryl alcohol, phenol and formaldehyde. However, most of the works have been involved only about the synthesis of pure carbon.

The doping of foreign atoms in the lattice of carbon has been receiving much attention because it changes the structural, mechanical and electronic properties of the carbon nanostructures [7]. This was first confirmed experimentally by Stephan et al [8] by the successful doping of boron and nitrogen in the carbon nanostructures using arc discharge method. Generally boron, nitrogen, cobalt, potassium, silicon, phosphorous and oxygen are used as dopants to modify the structure and properties of carbon. Boron [9] and nitrogen [10] atoms are the most conveniently used dopants, owing to their small atomic size which increases the probability to enter into the carbon lattice. Particularly, nitrogen doping has received much attention, as it not only changes the electronic properties but also affects the morphology of carbon nanostructures, reactivity and field emission properties [11]. Recently sharma et al [12] reported the synthesis of $B$ and $-N$ doped carbon nanotubes and observed that the field emission properties of carbon can be enhanced significantly. It has been also found that the concentration of dopant (boron or nitrogen) plays an important role in the doping of mesoporous carbon. Paez et al [13] reported that when the concentration of nitrogen in the carbon lattice increases, the concentration of reactive points in the wall of carbon nanotubes increases, thus causing clear electronic and structural differences.

Currently, synthesis of mesoporous carbon has been received much attention owing to their uniform pore structure, high surface area and large pore volume [14]. A variety of research has been carried out for the preparation of uni and three dimensional mesoporous carbons using uni and three dimensional mesoporous silica as the templates (MCM-48, SBA-15, HMS, MSU-H and MCM-41) [15-17]. Among these, mesoporous materials with three dimensional porous structure have attracted a significant attention owing to their excellent textural characteristics and unique 3D channel network which provide a highly opened porous host with easy and direct access for guest species, thus facilitating inclusion or diffusion throughout the pore channels without pore blockage. Recently Ryoo et al. have reported that three dimensional cage type mesoporous silica, KIT- 6 can be synthesized using a low cost polymeric P123 surfactant and $n$-butanol as a co-solvent. This material has received much attention because of its three dimensional structure with a large mesopores of diameter and easy synthesis method.

Here we report for the first time on the synthesis and characterization of novel N-doped mesoporous carbon (N-MC) using three dimensional cage type mesoporous silica, KIT-6 as the template. Aniline has been used as nitrogen source and polymerized by $\mathrm{NH}_{4} \mathrm{~S}_{2} \mathrm{O}_{8}$. The obtained material has been extensively characterized by sophisticated instruments such as powder X-ray diffraction, nitrogen adsorption measurement, CHN analysis and X-ray photoelectron spectroscopy. XPS 
studies revealed that nitrogen atom in mesoporous carbon exhibited two different structures such as pyridine and graphene.

\section{EXPERIMENTAL SECTION}

Synthesis of KIT6: Synthesis of large pore cubic mesoporous KIT6 is carried out in poly propylene bottle and the typical synthesis procedure is described below: $4.0 \mathrm{~g}$ of $\mathrm{P} 123$ was dissolved in $144 \mathrm{~g}$ of distilled water and $7.9 \mathrm{~g}$ of $35 \mathrm{wt} \% \mathrm{HCl}$ solution and stirred at $308 \mathrm{~K}$. After complete dissolution, $4.0 \mathrm{~g}$ of $n$-butanol was added and stirred for another hour. $8.6 \mathrm{~g}$ of TEOS was added to the homogeneous clear solution and vigorously stirred at $308 \mathrm{~K}$ for $24 \mathrm{~h}$. The resulting gel was aged at $373 \mathrm{~K}$ for $24 \mathrm{~h}$ under static conditions. The white precipitated product was filtered hot without washing and dried at $373 \mathrm{~K}$ for $24 \mathrm{~h}$ in an air oven.

In a typical synthesis of $\mathrm{N}_{2}$-doped KIT-6, $0.5 \mathrm{~g}$ of calcined KIT- 6 was added to $2.525 \mathrm{~g}$ of aniline and mixed thoroughly. $3.5 \mathrm{~g}$ of ammonium peroxidisulfate $\left(\mathrm{NH}_{4} \mathrm{~S}_{2} \mathrm{O}_{8}\right)$ was added to the above mixture and the resultant greenish black mixture was heated at $273 \mathrm{~K}$ for overnight. Then, the obtained greenish solid mixture was ground onto a fine powder. $3.0 \mathrm{~g}$ of ammonium peroxidisulfate $\left(\mathrm{NH}_{4} \mathrm{~S}_{2} \mathrm{O}_{8}\right)$ was again added to the aforementioned material to enhance the polymerization of unreacted aniline molecules and dried in a vaccum oven at room temperature for $24 \mathrm{~h}$. The template$\mathrm{N}$-doped carbon polymer composite was then heat treated in a nitrogen flow of $100 \mathrm{~mL} \mathrm{~min}{ }^{-1-}$ at 1173 $\mathrm{K}$ with a heating rate of $3 \mathrm{~K} \mathrm{~min}^{-1}$ and kept under these conditions for $5 \mathrm{~h}$ to carbonize the polymer. The $\mathrm{N}$-doped mesoporous carbon was recovered after dissolution of the silica framework in $5 \mathrm{wt} \%$ hydrofluoric acid followed by filtration, washed several times with ethanol, and dried at $373 \mathrm{~K}$. The material is referred as N-MC. The powder $\mathrm{X}$-ray diffraction (XRD) pattern of $\mathrm{N}$-doped mesoporous carbon was collected on a Rigaku diffractometer using $\mathrm{Cu} \mathrm{Ka} \quad(\lambda=0.154 \mathrm{~nm})$ radiation. The diffractograms were recorded in the $2 \theta$ range of 0.8 to $10^{\circ}$ with a $2 \theta$ step size of $0.01^{\circ}$ and a step time of $1 \mathrm{~s}$. Nitrogen adsorption and desorption isotherms were measured at $77 \mathrm{~K}$ on a Quantachrome Autosorb 1 sorption analyzer. All samples were outgassed at $523 \mathrm{~K}$ for $3 \mathrm{~h}$ prior to the nitrogen adsorption measurements. The specific surface area was calculated with the use of the Brunauer-Emmett-Teller BET) method. X-ray photoelectron spectroscopy measurement was carried out on a Fisons Instrument using $\mathrm{Mg}-\mathrm{K} \alpha$ as the source.

\section{RESULTS AND DISCUSSION}

3.1 X-ray powder diffraction

The structural ordering of the $\mathrm{N}$-doped mesoporous carbon is investigated by powder $\mathrm{X}$-ray diffractometer and the XRD pattern $\mathrm{N}$-doped mesoporous carbon along with the parent silica template, KIT-6 is shown in Fig.1. The XRD pattern of KIT- 6 gives rise to well ordered XRD reflections which can be assigned to (211) (220)

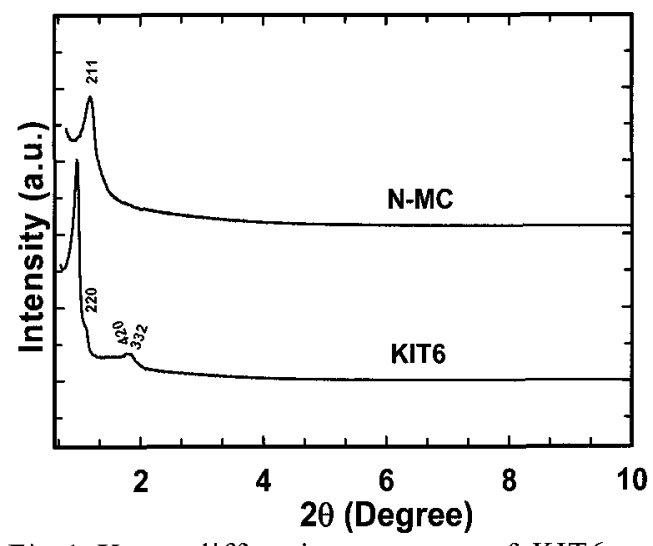

Fig.1 X-ray diffraction patterns of KIT6 and NMC

(321) and (420) diffractions of the cubic Ia3d symmetry. The XRD pattern of N-doped mesoporous carbon also exhibits a well resolved peak in the low $2 \theta$ region at $2 \theta=0.8^{0}$ which indicates that $\mathrm{N}$-doped mesoporous carbon possesses well ordered structure and the structural ordering of the mesoporous material, KIT-6 is replicated in the carbon material. It is interesting to note that the structure of $\mathrm{N}$-doped mesoporous carbon is almost similar to that of mesoporous silica, but with lower intensity, confirming that mesoporous silica framework is retained even after the high temperature carbonization step. The reduction in the intensity of the carbon can be assigned to the presence of nitrogen atom that interconnects effectively two enantiomeric channel systems in the bi-continuous mesoporous silica.

\subsection{Nitrogen adsorption measurements}

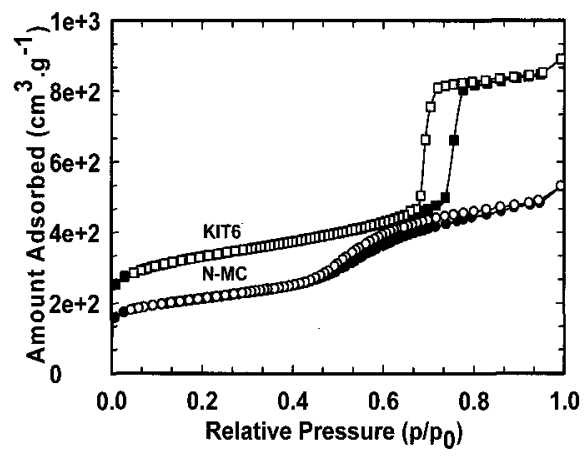

Fig.2. Nitrogen adsorption- desorption isotherm of KIT- 6 and N-MC

The nitrogen adsorption- desorption isotherm of $\mathrm{N}$-doped mesoporous carbon is shown in Fig. 2. For comparison, the adsorption-desorption isotherm of mesoporous KIT-6 also included in Fig. 2. Nitrogen adsorption-desorption isotherm of $\mathrm{N}$-doped mesoporous carbon showed Type IV isotherm which is typically observed for mesoporous material. The surface area and pore volume of $\mathrm{N}$-doped mesoporous carbon is 726.2 $\mathrm{m}^{2} / \mathrm{g}$ and $0.8212 \mathrm{~cm}^{3} / \mathrm{g}$, respectively. The pore volume of $\mathrm{N}$-doped mesoporous carbon is less compared to mesoporous silica. The adsorption pore size distribution of KIT- 6 and N-doped 
mesoporous carbon is 8.42 and $4.6 \mathrm{~nm}$ respectively. The decrease in the pore diameter of $\mathrm{N}$-doped mesoporous carbon reveals the framework shrinkage and successful replication.

\subsection{CHN Analysis}

The elemental composition of $\mathrm{N}$-doped mesoporous carbon was investigated by CHN analysis and the results are presented in Table 1 . It is observed from the Table that the overall carbon to nitrogen ratio is 13.21 . $\mathrm{H}$ and other elements such as $\mathrm{O}$ and $\mathrm{S}$ are also present along with carbon and nitrogen.

Table 1. Elemental composition of $\mathrm{N}$-doped mesoporous carbon obtained from CHN analysis

\begin{tabular}{|c|c|c|c|c|}
\hline Material & $\begin{array}{c}\mathrm{C} / \\
{[\mathrm{Wt} .-\%]}\end{array}$ & $\begin{array}{c}\mathrm{N} / \\
{[\mathrm{Wt} . \%]}\end{array}$ & $\begin{array}{c}\mathrm{H} / \\
{[\mathrm{Wt} .-\%]}\end{array}$ & $\begin{array}{l}\text { Others } \\
{[\text { Wt.-\%] }}\end{array}$ \\
\hline N-MC & 76.92 & 5.79 & 1.43 & 15.86 \\
\hline
\end{tabular}

3.4 X-ray photoelectron spectroscopy analysis $\mathrm{X}$-ray photoelectron spectroscopy of $\mathrm{N}$-doped mesoporous carbon was carried out to find out the chemical bonding between carbon and nitrogen, and the results are discussed as follows. The Cls spectrum of N-MC shows three peaks centered at about $289.40,284.92$ and $283.70 \mathrm{eV}$. The peak at $283.70 \mathrm{eV}$ for is assigned to pure graphitic sites in the mesoporous carbon while the peak centered at about $284.92 \mathrm{eV}$ corresponds to $\mathrm{sp}^{2} \mathrm{C}$ atoms bonded to nitrogen atom inside the aromatic structure $[18,19]$. The peak at $289.4 \mathrm{eV}$ is assigned to $\mathrm{sp}^{2}$ hybridized carbon in the aromatic ring attached to $\mathrm{NH}_{2}$ groups. The $\mathrm{N} 1 \mathrm{~s}$ spectrum of $\mathrm{N}-\mathrm{MC}$ could be deconvoluted into two peaks which are centered at about 397.34 and $399.98 \mathrm{eV}$. The peak at the binding energies of 397.34 and 399.98 $\mathrm{eV}$ corresponds to pyridinic and graphitic nitrogen respectively $[20,21]$. The term pyridine is used to refer $\mathrm{N}$ atoms which contribute to the pi system with one p-electron, whereas graphitic nitrogen corresponds to a highly coordinated $\mathrm{N}$ atom substituting inner $\mathrm{C}$ atoms on the graphene layers.

\section{CONCLUSION}

We have presented the synthesis and characterization of $\mathrm{N}$-doped mesoporous carbon via templating technique using three dimensional mesoporous material, KIT- 6 as solid template and aniline as nitrogen source. $\left(\mathrm{NH}_{4}\right)_{2} \mathrm{~S}_{2} \mathrm{O}_{8}$ was used to polymerize aniline molecules. X-ray diffraction pattern of $\mathrm{N}$-doped mesoporous carbon exhibited a well ordered mesoporous nature of the material, high surface area and pore volume. CHN analysis of $\mathrm{N}$-doped mesoporous carbon revealed that it contains only $5 \mathrm{wt} \%$ of nitrogen. XPS analysis indicates that nitrogen atom in the material exists atleast in two different states of chemical bonding, presumably pyridine and graphene like structure. We believe that this material may have the potential to enhance the mechanical, conducting, field emission, energy storage, and electron transport properties of the carbon nanostructures.

\section{REFERENCES}

[1]. Z.Yang, Y. Xia and R. Mokaya, $A d v$. Mater.,16,727(2004)

[2]. M. Kang, S.H. Yi, H.I. Lee, J.E. Yie and J.M. Kim, Chem. Commun., 1944 (2002)

[3]. T. Kyotani, Z.X. Ma and A. Tomita, Carbon, 41,1451(2003)

[4]. S. Jun, S.H. Joo, R. Ryoo, M. Kruk, M Jaroniec, Z. Liu, T. Ohsuna and O.J. Terasaki, J. Am.Chem. Soc.,122, 10712 (2000)

[5]. R. Ryoo, S.H. Joo and S.J. Jun, J.Phys.Chem. B103, 7743 (1999)

[6]. F. Su, X.S. Zhao, L. Lu and Z. Zhou, Carbon, 42, 282 (2004)

[7]. M. Terrones, N. Grobert and H.Terrones, Carbon, 40, 1665 (2002)

[8]. O. Stephan, P.M. Ajayan, C. Colliex, Ph. Redlich, J.M. Lambert,P. Bernier and P. Lefin, Science, 266,1683 (1994)

[9]. S. Shiraishil, M. Kibe, T. Yokoyama, H. Kurihara, N.Patel, A. Oya, Y. Kaburagi and Y. Hishiyama, Appl. Phys., A82, 585 (2006)

[10]. K. Yamamoto, T. Kamimura and K. Matsumoto, Jpn. J. Appl. Phys., 44, 1611(2005)

[11]. R. Droppa Jr., C.T.M. Ribeiro, A.R. Zanatta, M.C. dos Santos and F. Alvarez, Phys. Rev., B.69045405 (2004)

[12]. R.B. Sharma, D.J. Late, D.S. Joag, A. Govindaraj and C.N.R. Rao, Chem. Phys. Lett., 428,102(2006)

[13]. F.V. Paez, A. Zamudio, A.L. Elias, H. Son, E.B. Barros, S.G. Chou, Y.A. Kim, H. Muramatsu, T. Kayashi, J. Kong, H.Terrones, G. Dresselhaus, M. Endo, M. Terrones and M.S.Dresselhaus, Chem.Phys.Lett., 424, 345 (2006)

[14]. A.Stein, Microporous Mesoporous Mater. 227. 44 (2001)

[15]. J. Lee, S.Yoon, T. Hyeon, S.M. Oh and K.B. Kim, Chem. Commun. 2177 (1999)

[16]. J. Lee, S. Yoon, S.M. Oh, C.H. Shin and T. Hyeon, Adv. Mater., 12, 359(2000)

[17]. B. Tian, S. Che, Z. Liu, X. Liu, W. Fan, T. Tatsumi, O. Terasaki and D. Zhao, Chem. Commun. 2726 (2003)

[18]. J. C. Sanchez-Lopez, C. Donnet, F. Lefebvre, C. Fernandez-Ramos and A. Fernandez, J. Appl.Phys. 90, 675(2001)

[19]. D. Marton, K. J. Boyd, A. H. Al-Bayati, S.S Todorov and J. W. Rabalais, Phys. Rev. Lett. 73,118 (1994).

[20]. Y. Xia and R. Mokaya, Chem. Mater. 17,1553 (2005)

[21]. R. Sen, B.C. Sathishkumar, A. Govindaraj, K.R. Harikumar, M.K. Renganathan and C.N.R. Rao, J.Mater.Chem. 7, 2335 (1997)

(Received January 5, 2007;Accepted Sepember 1, 2007) 